\title{
Variations in the four and a half LIM domains 1 gene (FHL1) are associated with fasting insulin and insulin sensitivity responses to regular exercise
}

\author{
M. Teran-Garcia - T. Rankinen - T. Rice • A. S. Leon • \\ D. C. Rao • J. S. Skinner • C. Bouchard
}

Received: 9 January 2007 / Accepted: 19 April 2007 / Published online: 23 June 2007

(C) Springer-Verlag 2007

\begin{abstract}
Aims/hypothesis The expression of the four and a half LIM domains 1 gene (FHL1) is increased in the muscle of individuals who show an improvement in insulin sensitivity index $\left(S_{\mathrm{I}}\right)$ after 20 weeks of exercise training. The aim of the present study was to investigate associations between three FHL1 single nucleotide polymorphisms (SNPs) and variables derived from an IVGTT, both in the sedentary state and in response to exercise training, in participants in the HERITAGE Family Study.
\end{abstract}

Electronic supplementary material The online version of this article (doi:10.1007/s00125-007-0733-x) contains supplementary material, which is available to authorised users.

\footnotetext{
M. Teran-Garcia · T. Rankinen · C. Bouchard $(\bowtie)$

Human Genomics Laboratory,

Pennington Biomedical Research Center,

6400 Perkins Road,

Baton Rouge, LA 70808, USA

e-mail: BouchaC@pbrc.edu

T. Rice $\cdot$ D. C. Rao

Division of Biostatistics,

Washington University School of Medicine,

St Louis, MO, USA
}

\section{A. S. Leon}

Laboratory of Physiological Hygiene and Exercise Science,

School of Kinesiology, University of Minnesota,

Minneapolis, MN, USA

D. C. Rao

Departments of Genetics and Psychiatry,

Washington University School of Medicine,

St Louis, MO, USA

\section{J. S. Skinner}

Department of Kinesiology, Indiana University,

Bloomington, IN, USA
Materials and methods SNPs were typed using fluorescence polarisation methodology. Analyses were performed separately by sex and in black and white individuals.

Results In black participants, no associations were found with any of the SNPs. In white women $(n=207)$, SNP rs9018 was associated with the disposition index $\left(D_{\mathrm{I}}\right)$, which is calculated as $S_{\mathrm{I}}$ generated from the MINMOD program $\left(\times 10^{-4} \min ^{-1}[\mu \mathrm{U} / \mathrm{ml}]^{-1}\right)$ multiplied by acute insulin response to glucose $\left(\mathrm{AIR}_{\mathrm{g}} ; \mathrm{pmol} / 1 \times 10 \mathrm{~min}\right)$, and the glucose disappearance index $\left(K_{\mathrm{g}}\right)$ training responses $(p=0.016$ and $p=0.008$, respectively). In white men $(n=222)$, all SNPs were associated with fasting glucose levels $(p \leq 0.05)$ and SNP rs2180062 with the insulin sensitivity index $\left(S_{\mathrm{I}}\right)$ $(p=0.04)$ in the sedentary state. Two SNPs were associated with fasting insulin training response. Fasting insulin decreased to a greater extent in carriers of the rs $2180062 \mathrm{C}$ allele $(p=0.01)$ and $\mathrm{rs} 9018 \mathrm{~T}$ allele $(p=0.04)$. With exercise training, $S_{\mathrm{I}}\left(\times 10^{-4} \mathrm{~min}^{-1}[\mu \mathrm{U} / \mathrm{ml}]^{-1}: 0.68 \pm 0.20\right.$ vs $-0.77 \pm$ $0.44, p=0.046), D_{\text {I }}(319 \pm 123$ vs $-528 \pm 260, p=0.006)$ and $K_{\mathrm{g}}$ (per $100 \mathrm{~min}: 0.09 \pm 0.04$ vs $-0.14 \pm 0.8, p=0.03$ ) improved more in the $\mathrm{C}$ allele carriers at rs 2180062 than in the $\mathrm{T}$ allele carriers.

Conclusions/interpretation Fasting insulin and $S_{\mathrm{I}}$ responses to exercise training were associated with DNA sequence variation in FHL1 in white men. Whether these associations exist only in white men remains to be investigated.

Keywords $F H L 1$ - Gene-exercise interaction · MINMOD . Polymorphism · Risk factors · SLIM1 - SLIMMER · KYO-T Single nucleotide polymorphism $\cdot$ SNP

Abbreviations
$\mathrm{AIR}_{g} \quad$ acute insulin response to glucose
$D_{\mathrm{I}} \quad$ disposition index
$K_{\mathrm{g}} \quad$ glucose disappearance index


$S_{\mathrm{G}} \quad$ glucose effectiveness

$S_{\mathrm{I}} \quad$ insulin sensitivity index

SNP single nucleotide polymorphism

$V \mathrm{O}_{2 \max }$ maximum volume of oxygen utilisation gene and insulin-related phenotypes in all subjects of HERITAGE. The associations were investigated in the sedentary state and in response to 20 weeks of an endurance training programme.

\section{Introduction}

The four and a half LIM domains 1 gene (FHL1, found on chromosome $\mathrm{Xp27.2)}$ is a member of the gene family encoding the LIM domain-containing proteins and is translated into three protein isoforms that are mainly produced in skeletal muscle [1-3]. LIM domains are cysteine-rich zinc finger motifs that provide an interface for protein-protein interactions found in nuclear and cytoplasmic proteins including homeodomain transcription factors and kinases [4]. LIM domain proteins play important biological roles in cytoskeleton organisation, cell fate determination and organ development [5]. Interestingly, one LIM domain gene (ISL1) has been identified as a positional candidate gene for obesity and leptin levels, and is suggested to be involved in body weight regulation and glucose homeostasis [6]. FHL1 mRNA is more abundant in oxidative fibres of skeletal muscle and its expression increases with passive stretch-induced hypertrophy [3].

Physical activity and diet play a role in the prevention of type 2 diabetes [7-10]. However, there is considerable heterogeneity in the metabolic responses to regular exercise. The HERITAGE Family Study has provided evidence for the genetic and non-genetic determinants of many phenotypes in the sedentary state and in response to training. We have reported on the familial resemblance for traits related to insulin and glucose metabolism both in the sedentary state and in response to exercise training [11, 12]. Among participants in HERITAGE, there was a $10 \%$ mean increase in the insulin sensitivity index $\left(S_{\mathrm{I}}\right)$ in response to the standardised 20 week training programme. The changes in the $S_{\mathrm{I}}$ were not correlated with the changes in body weight, waist circumference or cardiorespiratory endurance [13].

We recently reported differences in skeletal muscle gene expression patterns between HERITAGE participants who increased their $S_{\text {I }}$ with exercise training vs carefully matched subjects who showed no improvement [14]. Using microarray and RT-PCR methodologies, we identified the FHL1 gene as a novel candidate for the $S_{\mathrm{I}}$ training response. We found that FHL1 mRNA expression was increased by $70 \%$ in those who improved their $S_{\text {I }}$ with training [14].

Here we have expanded our study of the FHL1 gene as a novel candidate for the $S_{\mathrm{I}}$ training response by investigating the associations between DNA sequence variations in the

\section{Materials and methods}

The HERITAGE Family Study design and methods have been described previously [15]. Briefly, the study was designed to investigate the role of genetic factors in the cardiovascular and metabolic adaptations to 20 weeks of endurance training in white and in black families. All subjects were required to be sedentary and in good health and to meet a series of inclusion criteria [15]. The offspring were required to be aged $\geq 17$ years and the parents $\leq 65$ years. All participants were sedentary at baseline, defined as not having engaged in regular physical activity more than once a week over the previous 6 months. Participants were excluded if they had a BMI $>40 \mathrm{~kg} / \mathrm{m}^{2}$ (unless they were able to meet the demands of the exercise tests and exercise training programme), hypertension or were using lipid-lowering, hypoglycaemic or anti-hypertensive medication. For this report, we analysed data from 429 white adults (222 men, 207 women) and 173 black adults (70 men, 103 women). Of the white participants, 162 were parents (88 men, 74 women) and 267 were adult offspring (134 men, 133 women). Among the black participants, 42 were parents (15 men, 27 women) and 131 were offspring (55 men, 76 women). The Institutional Review Boards at the five participating centres of HERITAGE approved the study protocol. Written informed consent was obtained from each participant.

The programme has been described elsewhere $[15,16]$. Briefly, the exercise intensity of the 20 week programme was customised for each participant based on the heart rate to oxygen uptake relationship measured at baseline. During the first 2 weeks, the subjects trained at a heart rate corresponding to $55 \%$ of maximum volume of oxygen utilisation $\left(V \mathrm{O}_{2 \max }\right)$ for 30 min per session. Duration was gradually increased to $50 \mathrm{~min}$ per session and intensity to the heart rate associated with $75 \%$ of the baseline $V \mathrm{O}_{2 \max }$ and then sustained for the last 6 weeks. Training frequency was three times per week, with all training sessions performed under supervision on cycle ergometers in the laboratory at the participating clinical centres.

Measurement of glucose, insulin and IVGTT-derived variables Fasting plasma glucose and insulin levels were analysed at baseline and after the 20 week training programme, 1 day after the last training session. Glucose was measured enzymatically using a reagent kit (Diagnostic 
Chemicals, Oxford, CT, USA). Plasma insulin was determined using radioimmunoassay after polyethylene glycol separation [17]. Polyclonal antibodies (with a cross-reactivity $>90 \%$ with pro-insulin and presumably its conversion intermediates) were used [18]. Therefore, insulin refers to immunoreactive insulin defined as the sum of insulin, pro-insulin and split-proinsulin. The intra- and inter-assay coefficients of variation for baseline insulin were 7.7 and $10.3 \%$, respectively. During the IVGTT, no insulin or secretagogues were used. Details of these analyses have been reported previously [13]. A frequently sampled IVGTT was administered in the morning after an overnight fast of $12 \mathrm{~h}$. From the IVGTT data, $S_{\mathrm{I}}$, acute insulin response to glucose $\left(\mathrm{AIR}_{\mathrm{g}}\right)$, disposition index $\left(D_{\mathrm{I}}\right)$ and glucose effectiveness $\left(S_{\mathrm{G}}\right)$ were derived from the Minimal Model (MINMOD) Millennium software [19]. The $S_{\mathrm{I}}$ represents the increase in net fractional glucose clearance rate per unit change in serum insulin concentration after the intravenous glucose load. The $\mathrm{AIR}_{\mathrm{g}}$ was derived as the integrated area under the insulin curve between 0 and $10 \mathrm{~min}$ of the IVGTT and is used as a measure of insulin secretion [19]. The $D_{\mathrm{I}}$, calculated as $S_{\mathrm{I}}$ generated from the MINMOD program $\left(\times 10^{-4} \mathrm{~min}^{-1}[\mu \mathrm{U} / \mathrm{ml}]^{-1}\right)$ multiplied by AIR $_{\mathrm{g}}(\mathrm{pmol} / 1 \times 10$ $\mathrm{min}$ ), is a measure of the ability of the pancreatic beta cells to compensate for changes in insulin sensitivity. $S_{\mathrm{G}}$ measures the ability of glucose as such, independently of changes in plasma insulin, to increase glucose disposal and to suppress endogenous glucose output. Glucose disappearance index $\left(K_{\mathrm{g}}\right)$ estimates glucose disappearance based on the slope of the line derived from least-squares regression of the natural logarithm of plasma glucose from 10 to 60 min during the IVGTT and was used as a measure of overall glucose tolerance.

Molecular studies DNA was extracted from lymphoblastoid cell lines [20]. Genotyping for the FHL1 polymorphisms was performed with template-directed dye-terminator incorporation assay with fluorescence polarisation detection [21]. Briefly, genomic DNA containing the rs2180062 C $>$ T, rs2236003 $\mathrm{C}>\mathrm{T}$ and rs9018 $\mathrm{T}>\mathrm{C}$ single nucleotide polymorphisms (SNPs) located at chromosomal positions 134956908, 135015770 and 135018602 (dbSNP database, http://ncbi.nlm.nih.gov/projects/SNP, last accessed in May 2007) was amplified using PCR primers flanking the variant site. Unincorporated nucleotides and remaining unused primers were degraded by exonuclease I and shrimp alkaline phosphatase. Single base primer extension reactions were carried out with dye-terminators specific for the alleles present on the template. The genotype call rate was over $98 \%$ for all markers. A Mendelian check among the HERITAGE Families revealed no errors, and all SNPs were in Hardy-Weinberg equilibrium.
FHL1 haplotypes were constructed manually. In men, the phase of the haplotypes could be deducted directly from the SNP data. In women, the phases of the haplotypes in those who were heterozygotes at two or three SNP loci were confirmed using haplotype information from other family members: parents' haplotypes in daughters and sons' haplotype in mothers. There was only one double heterozygote in a white family, whose haplotype could not be confirmed. Results for the haplotypes in white individuals are presented in Electronic supplementary material (ESM) Tables 1 and 2.

Statistical analyses All statistical analyses were performed using the SAS Statistical Software package. In women, a $\chi^{2}$ test was performed to assess whether the observed genotype frequencies were in Hardy-Weinberg equilibrium. Sex-by-race subgroup association analyses were performed for the following reasons: (1) significant sex-related differences in fasting insulin and IVGTTderived variables; (2) location of the gene on the $\mathrm{X}$ chromosome; (3) racial differences for the baseline IVGTT phenotypes; and (4) significant racial differences in allele and genotype frequencies. The associations between FHL1 genotypes and phenotypes were analysed using a MIXED procedure. The non-independence among family members was adjusted using a 'sandwich estimator,' which asymptotically yields the same parameter estimates as ordinary least-squares or regression methods, but the standard errors and consequently hypothesis tests are adjusted for the familial dependencies. Age and BMI were included as covariates in the model. Because parents are unrelated individuals, they were analysed with a MIXED model, without non-independence adjustment. Fasting insulin and fasting glucose were logarithmically transformed, and the $S_{\mathrm{I}}, \mathrm{AIR}_{\mathrm{g}}$ and $D_{\mathrm{I}}$ variables were square root transformed to normalise their distributions before analysis. All training responses were adjusted for their respective baseline values.

\section{Results}

Frequencies of the rs $2180062 \mathrm{C}$, rs $2236003 \mathrm{C}$ and rs9018 T alleles in white individuals were $0.797,0.594$ and 0.522 , respectively; in black individuals, these frequencies were $0.378,0.793$ and 0.354 . Allele frequencies were comparable to those reported in the HAPMAP database (http:// www.HapMap.org, last accessed in May 2007). In women, genotype frequencies were in Hardy-Weinberg equilibrium. The markers were not in complete linkage disequilibrium, with $r^{2}=0.139,0.092$ and 0.288 in white participants, and $0.255,0.132$ and 0.235 in black participants, for the 
combinations rs $2180062 *$ rs 2236003 , rs $2180062 *$ rs 9018 and rs2236003*rs9018, respectively.

No significant associations with any of the SNPs were found in black individuals (see ESM Tables 3, 4, 5 for details).

Subject characteristics are presented in Table 1.

In the sedentary state, all three FHL1 polymorphisms were associated with fasting glucose levels in white men.

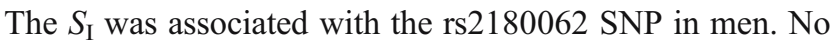
significant associations were found in women. Associations with fasting insulin, glucose and IVGTT-derived variables were seen in men in response to training.

In men, the rs2180062 C>T SNP, located within the $5^{\prime}$ UTR of the FHL1 gene, was associated with higher baseline glucose and exercise-induced changes in various measures of glucose homeostasis (Table 2). Men with the $\mathrm{C}$ allele had higher baseline glucose $(5.20 \pm 0.04 \mathrm{mmol} / 1$ [mean $\pm \mathrm{SE}])$ than those with the $\mathrm{T}$ allele $(5.06 \pm 0.07 \mathrm{mmol} / \mathrm{l}, p=0.02)$ and their fasting insulin levels decreased more with exercise training $(-9.1 \pm 2.0$ vs $+6.0 \pm 3.3 \mathrm{pmol} / 1, p=0.012)$. This reduction in fasting insulin with regular exercise was concordant with improvements in $S_{\mathrm{I}}, D_{\mathrm{I}}$ and $K_{\mathrm{g}}$. Men with the $\mathrm{C}$ allele had greater improvements in $S_{\mathrm{I}}\left(\times 10^{-4} \mathrm{~min}^{-1}[\mu \mathrm{U} /\right.$ $\left.\mathrm{ml}]^{-1}: 0.68 \pm 0.20 \mathrm{vs}-0.77 \pm 0.44, p=0.046\right), D_{\mathrm{I}}(+319 \pm 123$ vs $-528 \pm 260, p=0.006$ ) and $K_{\mathrm{g}}$ (per $100 \mathrm{~min}: 0.09 \pm 0.04 \mathrm{vs}$ $-0.14 \pm 0.8, p=0.03$ ) compared with the T allele carriers. To represent the differences in the $S_{\mathrm{I}}$ and $D_{\mathrm{I}}$ response according to the rs $2180062 \mathrm{C}>\mathrm{T}$ SNP in men, we plotted the pre- and post-training values for $S_{\mathrm{I}}$ and $\mathrm{AIR}_{\mathrm{g}}$ (Fig. 1). It can be seen that the improvements in $S_{\mathrm{I}}$ and $D_{\mathrm{I}}$ with exercise training in subjects with the $\mathrm{C}$ genotype were not at the expense of increased $\mathrm{AIR}_{\mathrm{g}}$.

The rs2236003 $\mathrm{C}>\mathrm{T}$ polymorphism, located in intron 3, was associated with fasting glucose at baseline in men (Table 3 ). Those with the $\mathrm{C}$ genotype had lower fasting glucose $(p=0.015)$. There were no associations in women.

In men, the rs9018 $\mathrm{T}>\mathrm{C}$ polymorphism, located at the $3^{\prime}$ UTR of the FHL1 gene, was associated with fasting glucose before training and with fasting glucose and insulin training responses; in women it was associated with the $D_{\mathrm{I}}$ response

Table 1 Characteristics of subjects

\begin{tabular}{|c|c|c|c|c|}
\hline \multirow[t]{2}{*}{ Variable } & \multicolumn{2}{|c|}{ Black individuals } & \multicolumn{2}{|c|}{ White individuals } \\
\hline & $\operatorname{Men}(n=70)$ & Women $(n=103)$ & Men $(n=222)$ & Women $(n=207)$ \\
\hline Age (years) & $33.1 \pm 11.1$ & $32.9 \pm 10.9$ & $36.5 \pm 14.9$ & $35.2 \pm 14.1$ \\
\hline \multicolumn{5}{|l|}{ BMI $\left(\mathrm{kg} / \mathrm{m}^{2}\right)$} \\
\hline Pre-training & $27.4 \pm 5.2$ & $28.2 \pm 6.0$ & $26.7 \pm 4.8$ & $25.2 \pm 5.0$ \\
\hline Training response & $-0.13 \pm 0.7$ & $-0.09 \pm 1.1$ & $-0.14 \pm 0.7$ & $-0.07 \pm 0.8$ \\
\hline \multicolumn{5}{|c|}{ Fasting plasma glucose $(\mathrm{mmol} / \mathrm{l})$} \\
\hline Pre-training & $5.27 \pm 0.63$ & $5.00 \pm 0.60$ & $5.20 \pm 0.60$ & $4.95 \pm 0.55$ \\
\hline Training response & $0.14 \pm 0.53^{\mathrm{a}}$ & $0.19 \pm 0.48^{\mathrm{a}}$ & $0.01 \pm 0.42$ & $0.04 \pm 0.37$ \\
\hline \multicolumn{5}{|c|}{ Fasting plasma insulin (pmol/l) } \\
\hline Pre-training & $72.3 \pm 43.9$ & $75.6 \pm 46.5$ & $71.1 \pm 44.8$ & $60.0 \pm 26.8$ \\
\hline Training response & $-4.9 \pm 27.2$ & $-5.4 \pm 21.9^{\mathrm{a}}$ & $-6.1 \pm 25.8^{\mathrm{a}}$ & $-3.7 \pm 21.1^{\mathrm{a}}$ \\
\hline \multicolumn{5}{|c|}{$S_{\mathrm{I}}\left(\times 10^{-4} \min ^{-1}[\mu \mathrm{U} / \mathrm{ml}]^{-1}\right)^{\mathrm{b}}$} \\
\hline Pre-training & $2.56 \pm 2.19$ & $2.80 \pm 2.19$ & $3.93 \pm 2.84$ & $4.75 \pm 2.99$ \\
\hline Training response & $0.49 \pm 1.94^{\mathrm{a}}$ & $0.33 \pm 2.16^{\mathrm{a}}$ & $0.46 \pm 2.70^{\mathrm{c}}$ & $0.00 \pm 2.66$ \\
\hline \multicolumn{5}{|c|}{$\mathrm{AIR}_{\mathrm{g}}(\mathrm{pmol} / 1 \times 10 \mathrm{~min})$} \\
\hline Pre-training & $1,510 \pm 1,362$ & $1,607 \pm 1,252$ & $739 \pm 614$ & $585 \pm 395$ \\
\hline Training response & $-85 \pm 575$ & $-46 \pm 495$ & $-64 \pm 341^{c}$ & $-20 \pm 213^{c}$ \\
\hline \multicolumn{5}{|l|}{$D_{\mathrm{I}}^{\mathrm{d}}$} \\
\hline Pre-training & $3,041 \pm 2,516$ & $3,528 \pm 2,897$ & $2,274 \pm 1,747$ & $2,394 \pm 1,672$ \\
\hline Training response & $480 \pm 2,457$ & $472 \pm 2,272$ & $185 \pm 1,663$ & $-54 \pm 1,542$ \\
\hline \multicolumn{5}{|l|}{$S_{\mathrm{G}}($ per $100 \mathrm{~min})$} \\
\hline Pre-training & $1.9 \pm 1.1$ & $2.0 \pm 1.2$ & $1.6 \pm 0.8^{\mathrm{a}}$ & $1.7 \pm 0.9$ \\
\hline Training response & $0.2 \pm 1.5$ & $0.3 \pm 1.5$ & $0.2 \pm 1.1^{\mathrm{a}}$ & $0.1 \pm 1.1$ \\
\hline \multicolumn{5}{|l|}{$K_{\mathrm{g}}($ per $100 \mathrm{~min})$} \\
\hline Pre-training & $1.70 \pm 0.68$ & $1.91 \pm 0.67$ & $1.54 \pm 0.57$ & $1.71 \pm 0.56$ \\
\hline Training response & $0.06 \pm 0.65$ & $0.13 \pm 0.64^{\mathrm{a}}$ & $0.06 \pm 0.53$ & $0.001 \pm 0.52$ \\
\hline
\end{tabular}

Data are means \pm SD

${ }^{a}$ Statistically significant response $(p<0.05)$ to exercise training

${ }^{\mathrm{b}}$ Units are taken from the MINMOD program. To convert values to SI units $\left(\times 10^{-4} \mathrm{~min}^{-1}\left[\mathrm{pmol} / \mathrm{ml}^{-1}\right) \mathrm{multiply} \mathrm{by} 0.167\right.$

${ }^{\mathrm{c}}$ Statistically significant response $(p<0.001)$ to exercise training

${ }^{\mathrm{d}} D_{\mathrm{I}}$ is calculated as $S_{\mathrm{I}}$ generated from the MINMOD program $\left(\times 10^{-4} \mathrm{~min}^{-1}[\mu \mathrm{U} / \mathrm{ml}]^{-1}\right)$ multiplied by AIR $(\mathrm{pmol} / 1 \times 10 \mathrm{~min})$ 
Table 2 Associations between the rs2180062 C > T FHL1 SNP and fasting glucose, insulin and IVGTT-derived variables in white individuals

\begin{tabular}{|c|c|c|c|c|c|c|c|c|c|c|c|c|}
\hline \multirow[t]{3}{*}{ Variable } & \multicolumn{7}{|c|}{ Women } & \multicolumn{5}{|l|}{ Men } \\
\hline & \multicolumn{2}{|c|}{$\mathrm{CC}, n=125$} & \multicolumn{2}{|c|}{$\mathrm{CT}, n=70$} & \multicolumn{2}{|c|}{$\mathrm{TT}, n=6$} & \multirow[b]{2}{*}{$p$ value } & \multicolumn{2}{|c|}{$\mathrm{CC}, n=176$} & \multicolumn{2}{|c|}{$\mathrm{TT}, n=40$} & \multirow[b]{2}{*}{$p$ value } \\
\hline & Mean & SE & Mean & SE & Mean & SE & & Mean & SE & Mean & SE & \\
\hline \multicolumn{13}{|c|}{ Fasting plasma glucose (mmol/1) } \\
\hline Pre-training ${ }^{\mathrm{a}}$ & 4.89 & 0.04 & 5.01 & 0.07 & 4.77 & 0.22 & 0.28 & 5.20 & 0.04 & 5.06 & 0.07 & 0.02 \\
\hline Training response ${ }^{\mathrm{b}}$ & 0.05 & 0.03 & 0.01 & 0.05 & 0.00 & 0.10 & 0.89 & -0.03 & 0.03 & 0.18 & 0.06 & 0.054 \\
\hline \multicolumn{13}{|c|}{ Fasting plasma insulin (pmol/l) } \\
\hline Pre-training ${ }^{\mathrm{a}}$ & 55.6 & 2.2 & 55.9 & 3.0 & 51.5 & 7.3 & 0.70 & 62.3 & 2.7 & 55.5 & 4.3 & 0.14 \\
\hline Training response $\mathrm{b}^{\mathrm{b}}$ & -5.3 & 1.8 & -1.5 & 3.0 & -7.3 & 4.4 & 0.53 & -9.1 & 2.0 & 6.0 & 3.3 & 0.012 \\
\hline \multicolumn{13}{|c|}{$S_{\mathrm{I}}\left(\times 10^{-4} \min ^{-1}[\mu \mathrm{U} / \mathrm{ml}]^{-1}\right)^{\mathrm{c}}$} \\
\hline Pre-training ${ }^{\mathrm{a}}$ & 4.28 & 0.23 & 4.33 & 0.33 & 6.05 & 1.63 & 0.76 & 3.35 & 0.18 & 3.96 & 0.52 & 0.044 \\
\hline Training response $\mathrm{b}^{\mathrm{b}}$ & 0.06 & 0.22 & -0.11 & 0.32 & -0.95 & 0.91 & 0.83 & 0.68 & 0.20 & -0.77 & 0.44 & 0.046 \\
\hline \multicolumn{13}{|c|}{$\mathrm{AIR}_{\mathrm{g}}(\mathrm{pmol} / 1 \times 10 \mathrm{~min})$} \\
\hline Pre-training ${ }^{\mathrm{a}}$ & 592 & 31 & 563 & 45 & 517 & 46 & 0.63 & 679 & 39 & 723 & 84 & 0.35 \\
\hline Training response $\mathrm{b}^{\mathrm{b}}$ & -26 & 18 & -18 & 28 & 29 & 90 & 0.78 & -62 & 26 & -108 & 39 & 0.27 \\
\hline \multicolumn{13}{|l|}{$D_{\mathrm{I}}^{\mathrm{d}}$} \\
\hline Pre-training ${ }^{\mathrm{a}}$ & 2,300 & 125 & 2,219 & 187 & 2,942 & 713 & 0.77 & 2,048 & 112 & 2,398 & 282 & 0.08 \\
\hline Training response $\mathrm{b}^{\mathrm{b}}$ & -31 & 132 & -149 & 180 & 128 & 993 & 0.82 & 319 & 123 & -528 & 260 & 0.006 \\
\hline \multicolumn{13}{|l|}{$S_{\mathrm{G}}($ per $100 \mathrm{~min})$} \\
\hline Pre-training ${ }^{\mathrm{a}}$ & 1.7 & 0.1 & 1.7 & 0.1 & 1.6 & 0.6 & 0.73 & 1.5 & 0.1 & 1.6 & 0.1 & 0.43 \\
\hline Training response $\mathrm{b}^{\mathrm{b}}$ & 0.1 & 0.1 & 0.0 & 0.1 & 0.2 & 0.9 & 0.50 & 0.2 & 0.1 & 0.1 & 0.2 & 0.75 \\
\hline \multicolumn{13}{|l|}{$K_{\mathrm{g}}($ per $100 \mathrm{~min})$} \\
\hline Pre-training ${ }^{\mathrm{a}}$ & 1.72 & 0.05 & 1.72 & 0.07 & 1.83 & 0.23 & 0.99 & 1.52 & 0.04 & 1.61 & 0.08 & 0.15 \\
\hline Training response $\mathrm{e}^{\mathrm{b}}$ & 0.00 & 0.04 & -0.05 & 0.06 & 0.10 & 0.22 & 0.56 & 0.09 & 0.04 & -0.14 & 0.08 & 0.03 \\
\hline
\end{tabular}

Values are means $\pm \mathrm{SE}$

${ }^{a}$ Adjusted for age and baseline BMI

${ }^{\mathrm{b}}$ Adjusted for age and baseline BMI plus the respective baseline values

${ }^{\mathrm{c}}$ Units are taken from the MINMOD program. To convert values to SI units $\left(\times 10^{-4} \mathrm{~min}^{-1}[\mathrm{pmol} / \mathrm{ml}]^{-1}\right)$ multiply by 0.167

${ }^{\mathrm{d}} D_{\mathrm{I}}$ is calculated as $S_{\mathrm{I}}$ generated from the MINMOD program $\left(\times 10^{-4} \mathrm{~min}^{-1}[\mu \mathrm{U} / \mathrm{ml}]^{-1}\right)$ multiplied by $\mathrm{AIR}_{\mathrm{g}}(\mathrm{pmol} / \mathrm{l} \times 10 \mathrm{~min})$

to exercise training (Table 4). In the sedentary state, men with the $\mathrm{T}$ allele have higher fasting glucose $(p=0.05)$ and higher fasting insulin levels $(p=0.06)$ with lower $S_{\mathrm{I}}(p=0.059)$ than individuals with the $\mathrm{T}$ allele. In response to training, fasting glucose and insulin decreased to a greater extent in the $\mathrm{T}$ allele carriers than in those with the $\mathrm{C}$ allele $(p=0.04)$. In women, the TT genotype at the rs9018 SNP was associated with a significantly higher training-induced improvement in
Fig. 1 Pre- and post-training effects on $S_{\mathrm{I}}$ and $\mathrm{AIR}_{\mathrm{g}}$ for white men according to the C genotype $(n=176)$ a and T genotype $(n=40)$ b of the rs2180062 C $>$ T FHL1 SNP. Open circles, mean values pretraining; closed circles, mean values post-training. Error bars denote SE
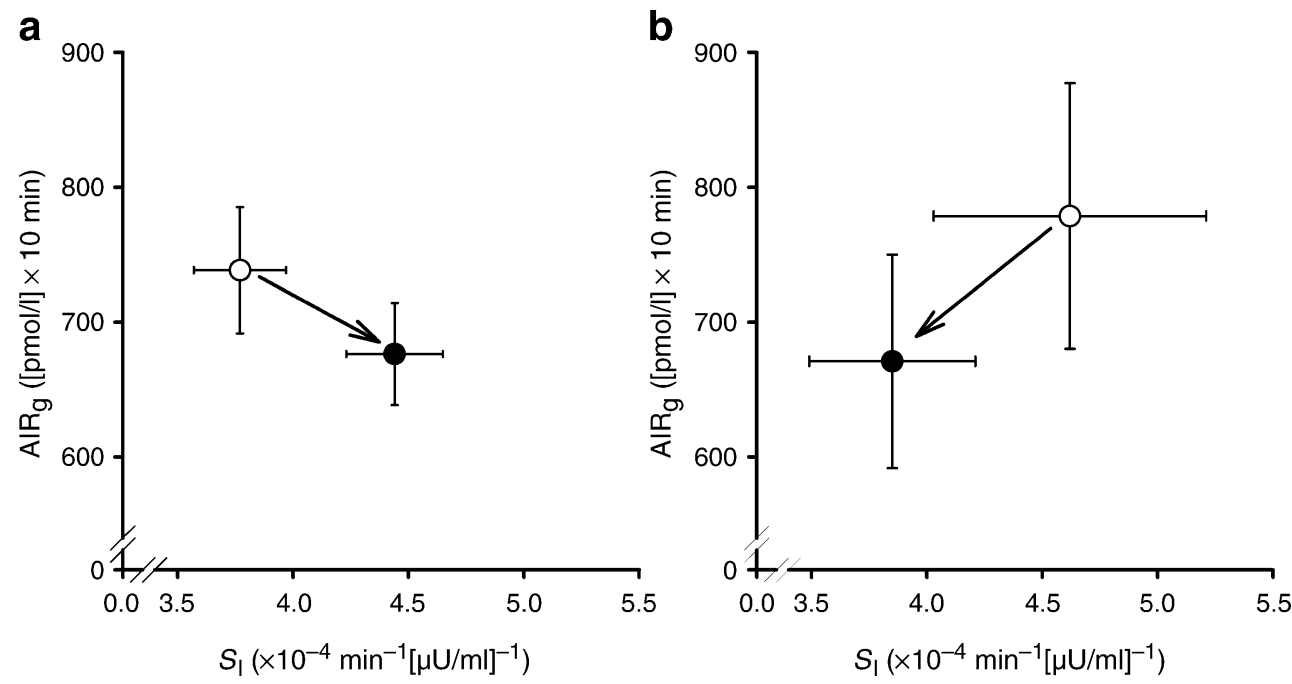
Table 3 Associations between the rs2236003 C > T FHL1 SNP and fasting glucose, insulin and IVGTT-derived variables in white individuals

\begin{tabular}{|c|c|c|c|c|c|c|c|c|c|c|c|c|}
\hline \multirow[t]{3}{*}{ Variable } & \multicolumn{7}{|c|}{ Women } & \multicolumn{5}{|l|}{ Men } \\
\hline & \multicolumn{2}{|c|}{$\mathrm{CC}, n=76$} & \multicolumn{2}{|c|}{$\mathrm{CT}, n=85$} & \multicolumn{2}{|c|}{$\mathrm{TT}, n=40$} & \multirow[b]{2}{*}{$p$ value } & \multicolumn{2}{|c|}{$\mathrm{CC}, n=123$} & \multicolumn{2}{|c|}{$\mathrm{TT}, n=92$} & \multirow[b]{2}{*}{$p$ value } \\
\hline & Mean & $\mathrm{SE}$ & Mean & SE & Mean & $\mathrm{SE}$ & & Mean & SE & Mean & SE & \\
\hline \multicolumn{13}{|c|}{ Fasting plasma glucose $(\mathrm{mmol} / \mathrm{l})$} \\
\hline Pre-training ${ }^{\mathrm{a}}$ & 4.90 & 0.06 & 4.98 & 0.06 & 4.85 & 0.07 & 0.54 & 5.09 & 0.04 & 5.29 & 0.07 & 0.015 \\
\hline Training response $\mathrm{e}^{\mathrm{b}}$ & 0.01 & 0.05 & 0.04 & 0.04 & 0.08 & 0.05 & 0.56 & 0.08 & 0.04 & -0.08 & 0.05 & 0.16 \\
\hline \multicolumn{13}{|c|}{ Fasting plasma insulin (pmol/l) } \\
\hline Pre-training ${ }^{\mathrm{a}}$ & 55.0 & 3.1 & 56.3 & 2.7 & 51.8 & 2.8 & 0.62 & 61.2 & 3.0 & 59.8 & 3.6 & 0.31 \\
\hline Training response & -6.9 & 2.5 & -2.4 & 2.4 & -1.8 & 3.0 & 0.57 & -4.0 & 2.3 & -10.3 & 2.8 & 0.059 \\
\hline \multicolumn{13}{|c|}{$S_{\mathrm{I}}\left(\times 10^{-4} \min ^{-1}[\mu \mathrm{U} / \mathrm{ml}]^{-1}\right)^{\mathrm{c}}$} \\
\hline Pre-training ${ }^{\mathrm{a}}$ & 4.55 & 0.34 & 4.11 & 0.28 & 4.22 & 0.32 & 0.69 & 3.47 & 0.24 & 3.48 & 0.25 & 0.38 \\
\hline Training response & -0.42 & 0.31 & 0.10 & 0.27 & 0.79 & 0.35 & 0.16 & 0.26 & 0.25 & 0.62 & 0.25 & 0.28 \\
\hline \multicolumn{13}{|c|}{$\operatorname{AIR}_{\mathrm{g}}(\mathrm{pmol} / 1 \times 10 \mathrm{~min})$} \\
\hline Pre-training ${ }^{\mathrm{a}}$ & 528 & 38 & 611 & 42 & 579 & 45 & 0.44 & 732 & 49 & 629 & 51 & 0.20 \\
\hline Training response & -19 & 24 & -13 & 25 & -48 & 33 & 0.40 & -73 & 30 & -78 & 34 & 0.27 \\
\hline \multicolumn{13}{|l|}{$D_{\mathrm{I}}^{\mathrm{d}}$} \\
\hline Pre-training ${ }^{\mathrm{a}}$ & 2,119 & 151 & 2,357 & 188 & 2,261 & 185 & 0.38 & 2,145 & 127 & 2,096 & 180 & 0.98 \\
\hline Training response & -104 & 154 & -129 & 186 & 230 & 210 & 0.52 & 193 & 154 & 33 & 154 & 0.38 \\
\hline \multicolumn{13}{|l|}{$S_{\mathrm{G}}($ per $100 \mathrm{~min})$} \\
\hline Pre-training ${ }^{\mathrm{a}}$ & 1.5 & 0.1 & 1.8 & 0.1 & 1.8 & 0.2 & 0.13 & 1.5 & 0.1 & 1.6 & 0.1 & 0.26 \\
\hline Training response & 0.3 & 0.2 & 0.0 & 0.1 & -0.1 & 0.1 & 0.77 & 0.3 & 0.1 & 0.1 & 0.1 & 0.77 \\
\hline \multicolumn{13}{|l|}{$K_{\mathrm{g}}($ per $100 \mathrm{~min})$} \\
\hline Pre-training ${ }^{\mathrm{a}}$ & 1.63 & 0.06 & 1.74 & 0.07 & 1.77 & 0.08 & 0.21 & 1.53 & 0.04 & 1.56 & 0.07 & 0.60 \\
\hline Training response & 0.01 & 0.05 & -0.02 & 0.06 & 0.06 & 0.07 & 0.65 & 0.07 & 0.05 & 0.01 & 0.06 & 0.41 \\
\hline
\end{tabular}

Values are means $\pm \mathrm{SE}$

${ }^{a}$ Adjusted for age and baseline BMI

${ }^{\mathrm{b}}$ Adjusted for age and baseline BMI plus the respective baseline values

${ }^{\mathrm{c}}$ Units are taken from the MINMOD program. To convert values to SI units $\left(\times 10^{-4} \mathrm{~min}^{-1}[\mathrm{pmol} / \mathrm{ml}]^{-1}\right)$ multiply by 0.167

${ }^{\mathrm{d}} D_{\mathrm{I}}$ is calculated as $S_{\mathrm{I}}$ generated from the MINMOD program $\left(\times 10^{-4} \mathrm{~min}^{-1}[\mu \mathrm{U} / \mathrm{ml}]^{-1}\right)$ multiplied by AIR $(\mathrm{pmol} / 1 \times 10 \mathrm{~min})$

$D_{\mathrm{I}}(p=0.016)$ and $K_{\mathrm{g}}(p=0.008)$. The association with the $D_{\mathrm{I}}$ response remained significant even after adjustments for BMI changes. In one individual with TT genotype we saw an extreme decrease of $S_{\mathrm{I}}\left(-12.2 \times 10^{-4} \mathrm{~min}^{-1}[\mu \mathrm{U} / \mathrm{ml}]^{-1}\right)$, which was included for the analysis presented here. However, when the analysis was performed excluding this individual, the genotype associations with $D_{\mathrm{I}}$ and $K_{\mathrm{g}}$ remained, but the significance levels changed to $p=0.004$ and $p=0.01$, respectively. No other associations with IVGTT-derived variables were found in women.

In white men, the rs2180062 C>T SNP explained 2.4, 3.3 and $2.4 \%$ of the variance for the fasting insulin response, $S_{\mathrm{I}}$ response and $D_{\mathrm{I}}$ response respectively.

\section{Discussion}

The objective of this study was to expand on our observation of the FHL1 gene as a novel candidate for the $S_{\text {I }}$ response to exercise training in all subjects of the HERITAGE Family Study [14]. Therefore, we tested for associations between FHL1 SNPs and insulin-related phenotypes at baseline and in response to regular exercise. All SNPs were associated with fasting glucose levels in men. In addition, the $\mathrm{C}$ allele carriers at the rs 2180062 SNP had greater improvements in the $S_{\mathrm{I}}$ and $D_{\mathrm{I}}$ response to exercise training.

It is well known that regular exercise leads to favourable changes in insulin sensitivity in most people [13]. However, the extent of the changes is highly variable and, in the HERITAGE Family Study, men had larger improvements in their $S_{\mathrm{I}}$ than women [13]. Why some individuals under the same exercise training protocol increase their insulin sensitivity while others do not is not understood at this time. In this regard, we have recently reported data on differences in gene expression from individuals selected on the basis of their $S_{\mathrm{I}}$ response to exercise training [14]. High and low responders had similar ages ( $30 \pm 5$ years), BMI, $\%$ body fat and baseline $S_{\mathrm{I}}$ but displayed marked differences in the $S_{\mathrm{I}}$ response to exercise training $\left(\times 10^{-4} \mathrm{~min}^{-1}\right.$ $[\mu \mathrm{U} / \mathrm{ml}]^{-1}: 3.6 \pm 0.5$ vs $-1.2 \pm 0.5, n=8$ per group). We identified FHL1 gene expression as one of the candidates responsible for the divergent $S_{\text {I }}$ response to exercise. 
Table 4 Associations between the rs9018 T>C FHL1 SNP and fasting glucose, insulin and IVGTT-derived variables in white individuals

\begin{tabular}{|c|c|c|c|c|c|c|c|c|c|c|c|c|}
\hline \multirow[t]{3}{*}{ Variable } & \multicolumn{7}{|c|}{ Women } & \multicolumn{5}{|l|}{ Men } \\
\hline & \multicolumn{2}{|c|}{$\mathrm{TT}, n=62$} & \multicolumn{2}{|c|}{$\mathrm{CT}, n=92$} & \multicolumn{2}{|c|}{$\mathrm{CC}, n=47$} & \multirow[b]{2}{*}{$p$ value } & \multicolumn{2}{|c|}{ TT, $n=110$} & \multicolumn{2}{|c|}{$\mathrm{CC}, n=104$} & \multirow[b]{2}{*}{$p$ value } \\
\hline & Mean & SE & Mean & SE & Mean & SE & & Mean & SE & Mean & SE & \\
\hline \multicolumn{13}{|c|}{ Fasting plasma glucose $(\mathrm{mmol} / \mathrm{l})$} \\
\hline Pre-training ${ }^{\mathrm{a}}$ & 4.93 & 0.06 & 4.95 & 0.06 & 4.89 & 0.07 & 0.98 & 5.25 & 0.06 & 5.10 & 0.05 & 0.05 \\
\hline Training response $\mathrm{b}^{\mathrm{b}}$ & 0.09 & 0.04 & 0.03 & 0.04 & 0.01 & 0.06 & 0.25 & -0.07 & 0.04 & 0.09 & 0.04 & 0.04 \\
\hline \multicolumn{13}{|c|}{ Fasting plasma insulin $(\mathrm{pmol} / \mathrm{l})$} \\
\hline Pre-training ${ }^{\mathrm{a}}$ & 53.7 & 3.0 & 57.7 & 2.4 & 52.8 & 3.9 & 0.35 & 65.3 & 3.6 & 57.2 & 2.9 & 0.06 \\
\hline Training response & -2.9 & 2.4 & -3.6 & 2.4 & -6.0 & 3.1 & 0.43 & -11.6 & 2.9 & -0.7 & 2.0 & 0.04 \\
\hline \multicolumn{13}{|c|}{$S_{\mathrm{I}}\left(\times 10^{-4} \mathrm{~min}^{-1}[\mu \mathrm{U} / \mathrm{ml}]^{-1}\right)^{\mathrm{c}}$} \\
\hline Pre-training ${ }^{\mathrm{a}}$ & 4.19 & 0.29 & 4.15 & 0.28 & 5.08 & 0.47 & 0.12 & 3.22 & 0.22 & 3.74 & 0.27 & 0.059 \\
\hline Training response & 0.48 & 0.31 & -0.13 & 0.26 & -0.56 & 0.45 & 0.11 & 0.50 & 0.20 & 0.22 & 0.31 & 0.90 \\
\hline \multicolumn{13}{|c|}{$\mathrm{AIR}_{\mathrm{g}}(\mathrm{pmol} / 1 \times 10 \mathrm{~min})$} \\
\hline Pre-training ${ }^{\mathrm{a}}$ & 583 & 39 & 616 & 41 & 497 & 46 & 0.38 & 697 & 55 & 678 & 46 & 0.67 \\
\hline Training response & 21 & 28 & -47 & 22 & -27 & 30 & 0.31 & -88 & 32 & -62 & 31 & 0.63 \\
\hline \multicolumn{13}{|l|}{$D_{\mathrm{I}}^{\mathrm{d}}$} \\
\hline Pre-training ${ }^{\mathrm{a}}$ & 2,243 & 155 & 2,340 & 173 & 2,271 & 227 & 0.87 & 2,067 & 160 & 2,165 & 136 & 0.88 \\
\hline Training response & 329 & 192 & -204 & 171 & -365 & 189 & 0.016 & 19 & 129 & 245 & 186 & 0.30 \\
\hline \multicolumn{13}{|l|}{$S_{\mathrm{G}}($ per $100 \mathrm{~min})$} \\
\hline Pre-training ${ }^{\mathrm{a}}$ & 1.8 & 0.1 & 1.7 & 0.1 & 1.5 & 0.1 & 0.18 & 1.6 & 0.1 & 1.5 & 0.1 & 0.23 \\
\hline Training response & 0.0 & 0.1 & 0.0 & 0.1 & 0.2 & 0.2 & 0.76 & 0.2 & 0.1 & 0.2 & 0.1 & 0.65 \\
\hline \multicolumn{13}{|l|}{$K_{\mathrm{g}}($ per $100 \mathrm{~min})$} \\
\hline Pre-training ${ }^{\mathrm{a}}$ & 1.80 & 0.07 & 1.74 & 0.06 & 1.63 & 0.08 & 0.39 & 1.56 & 0.06 & 1.51 & 0.05 & 0.33 \\
\hline Training response & 0.09 & 0.07 & -0.07 & 0.05 & -0.04 & 0.07 & 0.008 & 0.01 & 0.05 & 0.06 & 0.05 & 0.75 \\
\hline
\end{tabular}

Values are means $\pm \mathrm{SE}$

${ }^{a}$ Adjusted for age and baseline BMI

${ }^{\mathrm{b}}$ Adjusted for age and baseline BMI plus the respective baseline values

${ }^{\mathrm{c}}$ Units are taken from the MINMOD program. To convert values to SI units $\left(\times 10^{-4} \mathrm{~min}^{-1}[\mathrm{pmol} / \mathrm{ml}]^{-1}\right)$ multiply by 0.167

${ }^{\mathrm{d}} D_{\mathrm{I}}$ is calculated as $S_{\mathrm{I}}$ generated from the MINMOD program $\left(\times 10^{-4} \mathrm{~min}^{-1}[\mu \mathrm{U} / \mathrm{ml}]^{-1}\right)$ multiplied by AIR $(\mathrm{pmol} / 1 \times 10 \mathrm{~min})$

Unfortunately, we do not have individual RNA samples to verify sex-related differences in FHL1 expression levels.

FHL1 mRNA expression is increased in muscle with passive stretch-induced hypertrophy [22], is more abundant in skeletal muscle oxidative fibres [3] and increases in individuals who improve their $S_{\mathrm{I}}$ in response to exercise training [14]. FHL1 functions as a scaffold protein in the actin-based cytoskeleton, localises at focal adhesions and stress fibres and may be transferred to the nucleus by binding integrin proteins [4]. FHL1 plays an important role during the early stages of skeletal muscle differentiation, specifically in the $\alpha 5-\beta 1$-integrin-mediated signalling pathway [23]. SLIMMER, an FHL1 isoform, is found in the nucleus of myoblasts and in the cytoplasm of myotubes, suggesting distinct roles in the cytoskeleton and in nuclearcytoplasmic communication $[3,4]$.

The principal finding of our study is that regular physical activity decreased $S_{\mathrm{I}}$ and $D_{\mathrm{I}}$, while increasing fasting insulin levels in men with the less frequent $\mathrm{T}$ allele at the rs2180062 SNP (Fig. 1). These results are relevant since individuals with the $\mathrm{T}$ genotype represent almost $20 \%$ of the white population. The increment in fasting insulin levels associated with the $\mathrm{T}$ genotype training response could echo the decreased insulin sensitivity. Consequently, we observed a large fall in $D_{\mathrm{I}}$. Given the large variability in the response to exercise, those individuals with the T genotype seem to belong to a subgroup that does not benefit much in terms of IVGTT-derived variables, whereas those with the C genotype benefit substantially. This does not necessarily mean that men with the $\mathrm{T}$ genotype are at risk of developing diabetes, since other physiological benefits could be derived from an exercise training programme that could mitigate the $\mathrm{T}$ genotype effects.

Our data suggest that FHL1 may play a role in the improvements in IVGTT-derived variables induced by exercise training. DNA sequence variations in the FHL1 gene could possibly influence the capacity of skeletal muscle adaptation to the demands of exercise training. Probably FHL1 sequence variants impair its function as a scaffold protein in the integrin-mediated or other kinase signalling pathways, which in turn may reduce the metabolic effects of exercise on insulin sensitivity. The DNA variants studied here are not associated with amino acid changes in the FHLI gene, but may be functional. The 
SNP rs2180062, for example, localises at the $5^{\prime}$ UTR of one of the isoforms coded by this gene. A survey of this sequence for protein-binding regulatory elements using the AliBaba 2.1 search engine [24] reveals that this variant is located in a region with potential binding sites for the transcription factors CeMyoD (also known as HLH-1) and $\mathrm{Sp} 1$. In our in silico analysis, the $\mathrm{C} \rightarrow \mathrm{T}$ transition creates binding sites for the transcription factors NF-1 and AP-2, eliminating CeMyoD and Sp1 binding. The SNP rs9018 localises at the $3^{\prime}$ UTR region and could potentially affect stem-loop structure, processing and stability of mRNA [25]. To date, there are no experimental data to validate this concept.

The FHL1 gene localises in a region (Xp27.2) that is susceptible to inactivation. The fact that most of the associations presented here were not found in women might be due to the effects of random $\mathrm{X}$ chromosome inactivation on FHL1 production [26]. Perhaps a mechanism overriding expression of an allele associated with poor response to exercise training could result in a skewed distribution of muscle FHL1 production. This would result in slight exercise training changes and thus attenuate the genotype-phenotype associations [27]. Testing this hypothesis with female homozygotes for all three SNPs, we found a borderline significance for the $S_{\mathrm{I}}$ response $(p=0.06)$ at the rs2236003 SNP and confirmed the associations with $D_{\text {I }}$ and $K_{\mathrm{g}}$ at the rs9018 SNP.

The differences in the regular exercise-induced changes in fasting insulin accounted for by the FHL1 SNPs did not fully explain the heterogeneity in the responses. They account only for 2 to $3 \%$ of the variability in insulin sensitivity and fasting insulin responses. This should not be surprising, given the multifactorial and polygenic nature of the regulation of glucose-insulin metabolism. We did not find any significant associations in the black participants. While we have limited statistical power due to the small number of subjects for some genotypes, this ethnic difference remains to be fully investigated.

Caution is warranted when interpreting our findings. Although decreased $S_{\mathrm{I}}, D_{\mathrm{I}}$ and $K_{\mathrm{g}}$ responses to exercise training were associated with the $\mathrm{T}$ allele at the rs 2180062 SNP in male individuals, it could also be due to other reasons, such as a type I error (false-positive association). All the reported significance levels were nominal $p$ values and were not adjusted for multiple comparisons. If we had considered that at least 14 tests were performed in this report for each SNP and if the commonly suggested Bonferroni correction had been used, none of the tests would have reached statistical significance. However, the Bonferroni correction is not optimal in this case, because not all of these tests were independent. Only the replication of this study in other cohorts would allow verification of the validity of this initial finding.
The HERITAGE Family Study has revealed that regular exercise improves insulin sensitivity and glucose disposal, although there is large inter-individual variability in the degree of improvement. DNA sequence variations in the FHL1 gene could be related to these responses. Our data indicate that, in white men, the $\mathrm{T}$ allele at the rs 2180062 SNP in the FHL1 gene is associated with decreased $S_{\mathrm{I}}, D_{\mathrm{I}}$ and $K_{\mathrm{g}}$ responses to exercise training.

Acknowledgements The HERITAGE Family Study is supported by the National Heart, Lung, and Blood Institute Grants HL-45670 (C. Bouchard), HL-47323 (A. S. Leon), HL-47317 (D. C. Rao) and HL-47327 (J. S. Skinner). A. S. Leon is partially supported by the Henry L. Taylor endowed Professorship in Exercise Science and Health Enhancement and C. Bouchard is partially supported by the George A. Bray Chair in Nutrition. We thank J. H. Wilmore for his contribution to this study. We thank N. Laidlaw for editorial support.

Duality of interest The authors declare that there is no duality of interest associated with this manuscript.

\section{References}

1. Lee SM, Li HY, Ng EK et al (1999) Characterization of a brainspecific nuclear LIM domain protein (FHL1B) which is an alternatively spliced variant of FHL1. Gene 237:253-263

2. Lee SM, Tsui SK, Chan KK et al (1998) Chromosomal mapping, tissue distribution and cDNA sequence of four-and-a-half LIM domain protein 1 (FHL1). Gene 216:163-170

3. Loughna PT, Mason P, Bayol S, Brownson C (2000) The LIMdomain protein FHL1 (SLIM 1) exhibits functional regulation in skeletal muscle. Mol Cell Biol Res Commun 3:136-140

4. Brown S, McGrath MJ, Ooms LM, Gurung R, Maimone MM, Mitchell CA (1999) Characterization of two isoforms of the skeletal muscle LIM protein 1, SLIM1. Localization of SLIM1 at focal adhesions and the isoform slimmer in the nucleus of myoblasts and cytoplasm of myotubes suggests distinct roles in the cytoskeleton and in nuclear-cytoplasmic communication. $\mathrm{J}$ Biol Chem 274:27083-27091

5. Bach I (2000) The LIM domain: regulation by association. Mech Dev 91:5-17

6. Barat-Houari M, Clement K, Vatin V et al (2002) Positional candidate gene analysis of Lim domain homeobox gene (Isl-1) on chromosome $5 \mathrm{q} 11-\mathrm{q} 13$ in a French morbidly obese population suggests indication for association with type 2 diabetes. Diabetes 51:1640-1643

7. Tuomilehto J, Lindstrom J, Eriksson JG et al (2001) Prevention of type 2 diabetes mellitus by changes in lifestyle among subjects with impaired glucose tolerance. N Engl J Med 344:1343-1350

8. Knowler WC, Barrett-Connor E, Fowler SE et al (2002) Reduction in the incidence of type 2 diabetes with lifestyle intervention or metformin. N Engl J Med 346:393-403

9. Eriksson KF, Lindgarde F (1991) Prevention of type 2 (noninsulin-dependent) diabetes mellitus by diet and physical exercise. The 6-year Malmo feasibility study. Diabetologia 34:891-898

10. Duncan GE, Perri MG, Theriaque DW, Hutson AD, Eckel RH, Stacpoole PW (2003) Exercise training, without weight loss, increases insulin sensitivity and postheparin plasma lipase activity in previously sedentary adults. Diabetes Care 26:557-562 
11. Hong Y, Weisnagel SJ, Rice T et al (2001) Familial resemblance for glucose and insulin metabolism indices derived from an intravenous glucose tolerance test in Blacks and Whites of the HERITAGE Family Study. Clin Genet 60:22-30

12. An P, Hong Y, Weisnagel SJ et al (2003) Genomic scan of glucose and insulin metabolism phenotypes: the HERITAGE Family Study. Metabolism 52:246-253

13. Boule NG, Weisnagel SJ, Lakka TA et al (2005) Effects of exercise training on glucose homeostasis: the HERITAGE Family Study. Diabetes Care 28:108-114

14. Teran-Garcia M, Rankinen T, Koza RA, Rao DC, Bouchard C (2005) Endurance training-induced changes in insulin sensitivity and gene expression. Am J Physiol Endocrinol Metab 288:E1168E1178

15. Bouchard C, Leon AS, Rao DC, Skinner JS, Wilmore JH, Gagnon J (1995) The HERITAGE family study. Aims, design, and measurement protocol. Med Sci Sports Exerc 27:721-729

16. Skinner JS, Wilmore KM, Krasnoff JB et al (2000) Adaptation to a standardized training program and changes in fitness in a large, heterogeneous population: the HERITAGE Family Study. Med Sci Sports Exerc 32:157-161

17. Desbuquois B, Aurbach GD (1971) Use of polyethylene glycol to separate free and antibody-bound peptide hormones in radioimmunoassays. J Clin Endocrinol Metab 33:732-738

18. Roder ME, Porte D Jr, Schwartz RS, Kahn SE (1998) Disproportionately elevated proinsulin levels reflect the degree of impaired B cell secretory capacity in patients with noninsulin-dependent diabetes mellitus. J Clin Endocrinol Metab 83:604-608
19. Boston RC, Stefanovski D, Moate PJ, Sumner AE, Watanabe RM, Bergman RN (2003) MINMOD Millennium: a computer program to calculate glucose effectiveness and insulin sensitivity from the frequently sampled intravenous glucose tolerance test. Diabetes Technol Ther 5:1003-1015

20. Sambrook J, Fritsch E, Maniatis T (1989) Molecular cloning. Cold Spring Harbor Laboratory Press, Cold Spring Harbor, NY

21. Kwok PY (2002) SNP genotyping with fluorescence polarization detection. Human Mutat 19:315-323

22. Roth SM, Ferrell RE, Peters DG, Metter EJ, Hurley BF, Rogers MA (2002) Influence of age, sex, and strength training on human muscle gene expression determined by microarray. Physiol Genomics 10:181-190

23. McGrath MJ, Mitchell CA, Coghill ID, Robinson PA, Brown S (2003) Skeletal muscle LIM protein 1 (SLIM1/FHL1) induces $\alpha 5 \beta 1$-integrin-dependent myocyte elongation. Am J Physiol Cell Physiol 285:C1513-C1526

24. Grabe N (2002) AliBaba2: context specific identification of transcription factor binding sites. In Silico Biol 2:S1-S15

25. Grzybowska EA, Wilczynska A, Siedlecki JA (2001) Regulatory functions of 3' UTRs. Biochem Biophys Res Commun 288:291-295

26. Goto T, Monk M (1998) Regulation of X-chromosome inactivation in development in mice and humans. Microbiol Mol Biol Rev 62:362-378

27. Craig IW, Mill J, Craig GM, Loat C, Schalkwyk LC (2004) Application of microarrays to the analysis of the inactivation status of human X-linked genes expressed in lymphocytes. Eur J Hum Genet 12:639-646 